\title{
BMJ Open Characteristics and the average 30-day and 6-month clinical outcomes of patients hospitalised with coronary artery disease in a poor South-East Asian setting: the first cohort from Makassar Cardiac Center, Indonesia
}

\author{
Andriany Qanitha, ${ }^{1,2}$ Cuno S P M Uiterwaal, ${ }^{3}$ Jose P S Henriques, ${ }^{4}$ \\ Abdul Hakim Alkatiri, ${ }^{5}$ Idar Mappangara, ${ }^{5}$ Ali Aspar Mappahya, ${ }^{5}$ \\ Ilhamjaya Patellongi, ${ }^{2}$ Bastianus A J M de Mol ${ }^{1}$
}

To cite: Qanitha A, Uiterwaal CSPM, Henriques JPS, et al. Characteristics and the average 30 -day and 6-month clinical outcomes of patients hospitalised with coronary artery disease in a poor SouthEast Asian setting: the first cohort from Makassar Cardiac Center, Indonesia. BMJ Open 2018;8:e21996. doi:10.1136/ bmjopen-2018-021996

- Prepublication history and additional material for this paper are available online. To view these files, please visit the journal online (http://dx.doi. org/10.1136/bmjopen-2018021996).

The abstract of this manuscript has been presented in the American Heart Association (AHA) scientific event 2017, 11 November to 15 November 2017, in Anaheim, California, USA, and published in Circulation, 14 November 2017, Volume 136, Issue Suppl 1: A20914.

Received 31 January 2018 Revised 12 April 2018 Accepted 11 May 2018

Check for updates

For numbered affiliations see end of article.

Correspondence to Andriany Qanitha;

a.qanitha@amc.uva.nl; myaqanitha@gmail.com

\section{ABSTRACT}

Objective To provide a detailed description of characteristics at hospital admission and clinical outcomes at 30-day and 6-month follow-up in patients hospitalised with coronary artery disease (CAD) in a poor South-East Asian setting.

Design Prospective observational cohort study.

Setting From February 2013 to December 2014, in Makassar Cardiac Center, Indonesia.

Participants 477 patients with CAD (acute coronary syndrome and stable CAD).

Outcome measures All-cause mortality and major adverse cardiovascular events (MACE)

Results Out of 477 patients with CAD, the proportion of young age ( $<60$ years) was $53.9 \%$ and $72.7 \%$ were male. At admission, $44.2 \%$ of patients were diagnosed with STsegment elevation myocardial infarction (STEMI), 38.6\% with diagnosis or signs of heart failure and $75.1 \%$ had previous hypertension. Out of 211 patients with STEMI, only $4.7 \%$ had been treated with primary percutaneous coronary intervention $(\mathrm{PCl})$ and $6.2 \%$ received thrombolysis. The time lapse from symptom onset to hospital admission was 26.8 (IQR 10.0-48.0) hours, and $19.1 \%$ of all patients had undergone either $\mathrm{PCl}$ or coronary artery bypass graft. The survival rate at 6 months was $78.9 \%$. The rates of all-cause mortality at 30 days and 6 months were $13.4 \%$ and $7.3 \%$, respectively; the rate of composite MACE at 30 days was $26.2 \%$ and $18.0 \%$ at 6 months.

Conclusions Patients with CAD from a poor South-East Asian setting present themselves with predominantly unstable conditions of premature CAD. These patients show relatively severe illness, have significant time delay from symptom onset to admission or intervention, and most do not receive the guidelines-recommended treatment. Awareness of symptoms, prompt initial management of acute CVD, well-established infrastructures and resources both in primary and secondary hospital for CVD should be improved to reduce the high rates of 30-day and 6-month mortality and adverse outcomes in this population.
Strengths and limitations of this study

- This is the first study that fully reports on characteristics at admission as well as the short-term and mid-term outcomes of patients with coronary artery disease (CAD) in Indonesia.

- We completed, to the best of our ability, the follow-up of this study by actively visiting patients houses or contacting their family members to obtain outcomes data.

- Diversity on places of origin in our cohort represents the population in Indonesia, and generally represents a population in South-East Asia with limited resources.

- Due to geographical and distance constraints, follow-up was completed by telephone in half of this cohort.

- We excluded all patients with normal coronary angiography, and therefore our study might overlook the minor group of non-obstructive CAD.

\section{INTRODUCTION}

The South-East Asia region, which accounts for one-quarter of the world's population and $40 \%$ of the global poor, is facing a rapid epidemiological transition. ${ }^{1}$ This leads to the high rates of premature death from non-communicable diseases (NCD), primarily from cardiovascular disease (CVD) ${ }^{2}$ Of the 7.9 million annual NCD in this region, $34 \%$ occur before the age of 60 years compared with $16 \%$ in the European region and $23 \%$ in the rest of the world. ${ }^{2}$ Half of the world's cardiovascular burden is estimated to occur in Asia, ${ }^{3}$ and the prevalence of symptomatic heart failure appears to be higher in SouthEast Asia countries compared with the rest of 
the world. ${ }^{4}$ Despite the high burden of CVD in South-East Asia, little is known about characteristics at admission and clinical outcomes in patients with coronary artery disease (CAD), especially acute coronary syndrome (ACS).

Recent studies indicate the insufficient access to evidence-based interventions for combating CVD in low-income and middle-income countries. ${ }^{56}$ Particularly in Indonesia, the population of 260 million and a unique demographic situation (consisting of 17508 islands, over 6000 are inhabited) aggravate the inequity in the access to healthcare services, not only between the the rich and the poor, but also between rural and urban population within the country. Logistics and financial shortcomings, ${ }^{7}$ as well as the low awareness of the symptoms ${ }^{6}$ associated with CVD in these populations-resulted in delayed diagnosis and a younger age of death from CVD compared with the Western world. ${ }^{8}$ In Indonesia, there were approximately 760 cardiologists $^{9}$ and only 70 certified interventional cardiologists ${ }^{10}$ available to serve 883447 patients diagnosed with CAD and approximately 2650340 patients suspected with CAD in 2013. ${ }^{11}$ However, half of these cardiologists work on Java island and in the big cities, leaving other regions even less well served..$^{9}$

Besides the centralisation of healthcare facilities and the lack of healthcare professionals, $94.1 \%$ of households in 18 provinces in Indonesia are located more than $5 \mathrm{~km}$ from any primary healthcare centre or hospital ${ }^{12}$ with very minimal means of transportation and infrastructure. In addition, 28.6 million people (11.2\% of total population) are living at poor socioeconomic levels, ${ }^{13}$ and the majority were insufficiently health insured until $2013{ }^{7}$ Despite the fact that CVD ranks as the top cause of mortality in Indonesia, any follow-up studies of hospitalised patients with CAD (ACS and stable CAD (SCAD)) are rare.

Thus, in Indonesia there is clearly a general problem with access to care, but possibly also with the quality of care. It is suspected that many hospitalised patients who should be considered for early invasive strategy actually encounter delayed or overly conservative approaches. We studied the characteristics and clinical profiles of patients with CAD presenting at the Makassar Cardiac Center, Indonesia. These patient outcomes were evaluated in hospital, at 30 days and at 6 months.

\section{METHODS}

\section{Study population}

This was an observational cohort study of 477 consecutive patients who presented between February 2013 and December 2014 with a diagnosis of CAD at the Makassar Cardiac Center, Wahidin Sudirohusodo Hospital, one of the two public cardiac referral centres in East Indonesia. The cardiac centre with seven cardiologists mainly serves the 9.5 million South Sulawesi population, and also other regions inside and outside Sulawesi island.

Patients were included if they had confirmed CAD, defined as ACS and SCAD. ACS was defined as a spectrum of clinical presentations consistent with acute cardiac ischaemia within 24 hours of hospital presentation, including unstable angina (UA), non-ST-segment elevation myocardial infarction (NSTEMI) and STEMI. ${ }^{14} 15$ SCAD was defined as at least one of the following criteria: stable angina, history of UA, prior MI, prior coronary revascularisation (percutaneous coronary intervention (PCI) and/or coronary artery bypass graft (CABG)), or multivessel CAD without revascularisation. ${ }^{16}$ All eligible patients signed written informed consent before the first interview. We excluded all fatal patients who immediately died at the emergency department or cardiovascular intensive care unit before being able to give informed consent, and all suspected patients with normal coronary angiography (CAG) (defined as $0 \%$ lumen stenosis in all coronary vessels). ${ }^{17}$ The flow chart of the study population is presented in figure 1.

\section{Data collection and follow-up}

At hospital admission, we obtained baseline data from medical records and questionnaire interviews. Data on sociodemographic characteristics included age, gender, occupation, living area, monthly income and educational level; lifestyle included smoking status, dietary pattern and physical activity; family history of CVD included family history of premature sudden death at age $<60$ years ${ }^{18}$; clinical profiles included characteristics and onset of chest pain, previous medications, as well as history of previous diseases (ie, hypertension, type 2 diabetes mellitus, MI, stroke and kidney disease). Detailed methods were presented as online supplementary material.

Clinical data were collected prospectively at the time of hospital admission based on physical examination including vital signs, anthropometric measurements (ie, height, weight and waist circumference), electrocardiography, echocardiography including left ventricular ejection fraction (LVEF), CAG, laboratory tests including cardiac enzymes and estimated glomerular filtration rate. In-hospital managements and at-discharge medications were also recorded. Plasma glucose, lipid profiles, uric acid, renal and liver functions were measured within 24 hours of hospital admission following a minimum 8 hours fast for all patients hospitalised at Wahidin Sudirohusodo Hospital. While, for patients who were referred from other hospitals or clinics $(n=70)$, we obtained baseline and laboratory data from their medical records. All blood samples analyses were generated with standardised methods at the hospital laboratory.

Furthermore, data on mortality and major adverse cardiovascular events (MACE) were obtained during hospitalisation, at 30 days and at 6 months after hospital admission. For referred patients, we obtained data on in-hospital mortality from their family members and this was confirmed with hospital medical records from where the patients were admitted $(n=1)$. We actively performed the follow-up by visiting patient's houses or by an interview via telephone. The nurses asked a detailed questionnaire about patient's current condition, cardiovascular complaints, rehospitalisation, deaths and other 


\section{Total CVD patients in Makassar Cardiac Center, RSWS}

From February 2013 to December $2014(n=1,084)$

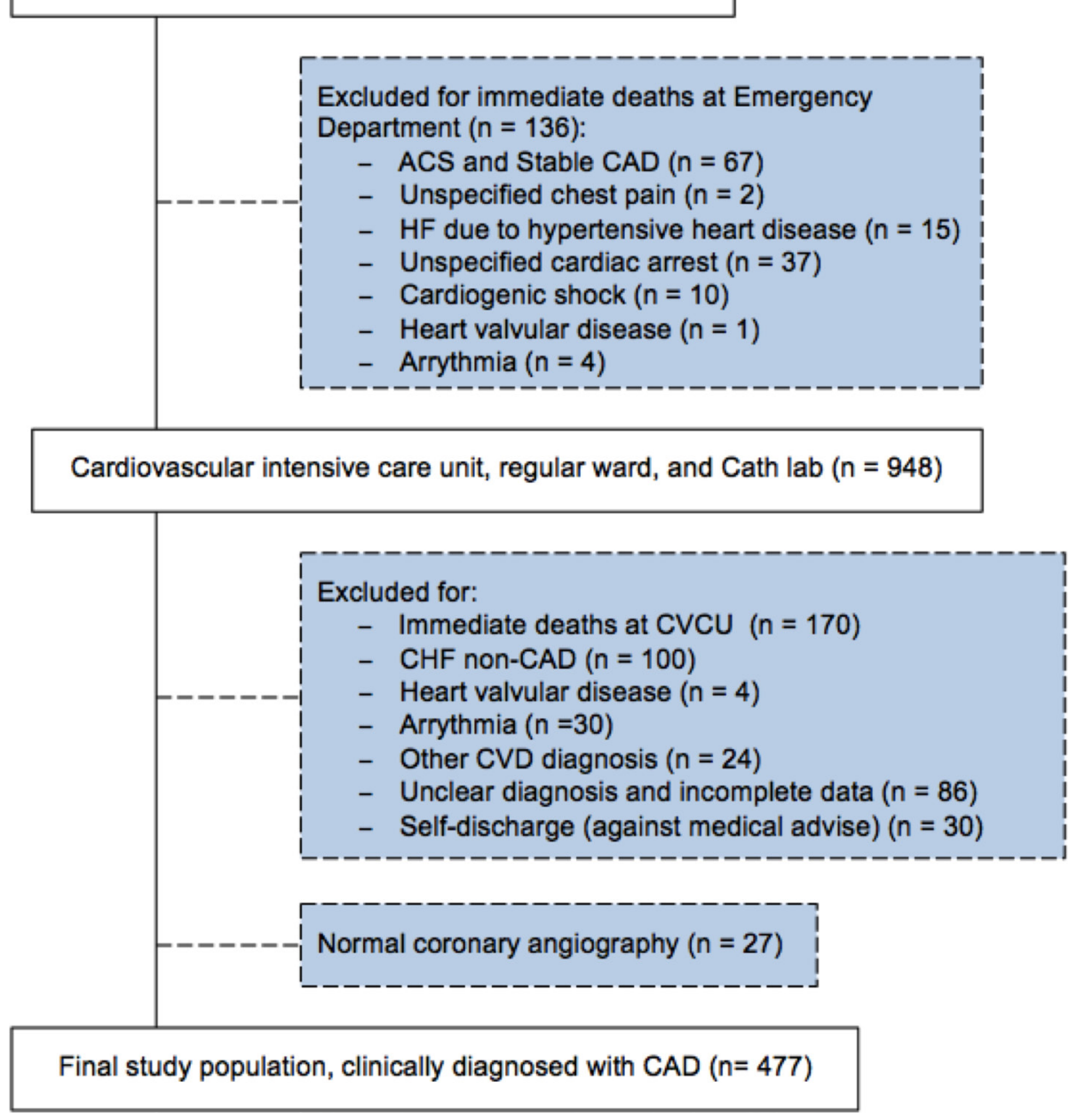

Figure 1 Flow chart of the study population. ACS, acute coronary syndrome; CAD, coronary artery disease; CHF, congestive heart failure; CVD, cardiovascular disease; HF, heart failure; RSWS: Rumah Sakit Wahidin Sudirohusodo (Wahidin Sudirohusodo hospital).

CVD-related events from the patients, family members or their relatives. Subsequently, we verified their answers with the medical records in hospital, or with the patient's documentation at home.

\section{Study outcomes}

The primary endpoints of our study were the rates of in-hospital, 30-day and 6-month all-cause mortality and composite MACE. The composite MACE counting for cardiac and non-cardiac death, MI rehospitalisation, heart failure requiring hospitalisation, rehospitalisation due to stroke, (emergency) CABG, stent thrombosis, repeat PCI, repeat CAG, first PCI and first CAG.

\section{Statistical analysis}

Continuous variables were presented as mean $\pm \mathrm{SD}$, and categorical variables as number (percentage). Skewed data were provided as median (Q1-Q3). Baseline characteristics, clinical profiles and managements during hospitalisation were divided into acute (ACS) and non-acute (SCAD) groups. The rates of mortality and composite MACE in hospital, at 30 days and at 6 months after hospital admission were calculated. Kaplan-Meier curves were used to describe the cumulative survival during 6-month follow-up. Log rank statistics were used to assess the difference between guideline-treated and non-guideline-treated groups. A 95\% CI not including one, corresponding to a two-sided $\mathrm{p}<0.05$ was considered statistically significant. All statistical analyses were performed using SPSS V.23.0.

\section{Patient involvement}

Patients were not involved in the design and development of the research questions. The results of this study are used to provide information for the stakeholders and health-policy makers to improve healthcare services in Indonesia. Therefore, the findings of our study were not disseminated directly to all participants.

\section{RESULTS}

Among 477 patients hospitalised with CAD, 257 (53.9\%) were at young age $(<60$ years $),{ }^{19}$ and $347(72.7 \%)$ were male. 
Table 1 Baseline characteristics at hospital admission

\begin{tabular}{|c|c|c|c|c|}
\hline & ACS & SCAD & Total & \\
\hline Variables & $(n=364)$ & $(n=113)$ & $(\mathrm{n}=477)$ & $P$ values \\
\hline Age (years) & $57.5 \pm 11.2$ & $60.6 \pm 8.8$ & $58.2 \pm 10.8$ & 0.007 \\
\hline Male & $260(71.4)$ & $87(77.0)$ & $347(72.7)$ & 0.246 \\
\hline Systolic BP (mm Hg) & $130.0 \pm 27.6$ & $127.3 \pm 20.4$ & $129.4 \pm 26.1$ & 0.336 \\
\hline Diastolic BP (mm Hg) & $82.7 \pm 16.1$ & $80.8 \pm 10.3$ & $82.2 \pm 14.9$ & 0.228 \\
\hline Fasting plasma glucose $(\mathrm{mmol} / \mathrm{L})^{*}$ & $7.3(5.8-9.6)$ & $5.9(5.1-8.2)$ & $7.0(5.7-9.1)$ & $<0.001$ \\
\hline Total cholesterol $(\mathrm{mmol} / \mathrm{L})^{\star}$ & $5.0(4.2-5.7)$ & $5.1(3.7-5.6)$ & $5.0(4.1-5.7)$ & 0.233 \\
\hline Triglycerides $(\mathrm{mmol} / \mathrm{L})^{\star}$ & $1.4(1.1-1.9)$ & $1.5(1.0-1.9)$ & $1.5(1.1-1.9)$ & 0.654 \\
\hline HDL-chol (mmol/L) & $0.95 \pm 0.31$ & $0.92 \pm 0.35$ & $0.94 \pm 0.32$ & 0.456 \\
\hline LDL-chol $(\mathrm{mmol} / \mathrm{L})^{*}$ & $3.3(2.6-4.0)$ & $3.2(2.3-3.7)$ & $3.3(2.6-3.9)$ & 0.032 \\
\hline Waist circumference (cm) & $84.6 \pm 7.4$ & $84.9 \pm 6.1$ & $84.6 \pm 7.1$ & 0.666 \\
\hline Obese $\left(\mathrm{BMI} \geq 25 \mathrm{~kg} / \mathrm{m}^{2}\right)$ & $119(32.7)$ & $46(40.7)$ & $165(34.6)$ & 0.118 \\
\hline Metabolic syndrome $†$ & $208(57.1)$ & $56(49.6)$ & $264(55.3)$ & 0.157 \\
\hline Parental history of CVD $\ddagger$ & $95(26.1)$ & $27(23.9)$ & $122(25.6)$ & 0.639 \\
\hline Monthly income $\geq$ Rp1 $810000 \S$ & $155(42.6)$ & $74(65.5)$ & $229(48.0)$ & $<0.001$ \\
\hline College education & $134(36.8)$ & $55(48.7)$ & $189(39.6)$ & 0.024 \\
\hline Living $>20 \mathrm{~km}$ from hospital (rural) & $193(53.0)$ & $54(47.8)$ & $247(51.8)$ & 0.331 \\
\hline \multicolumn{5}{|l|}{ Funding/insurance } \\
\hline Private fund (high income) & $30(8.2)$ & $6(5.3)$ & $36(7.5)$ & 0.303 \\
\hline Jamsostek (company)ף & $10(2.7)$ & $0(0.0)$ & $10(2.1)$ & 0.127 \\
\hline Askes (middle income) & $144(39.6)$ & $97(85.8)$ & $241(50.5)$ & $<0.001$ \\
\hline Jamkesmas/Jamkesda (low income) & $107(29.4)$ & $8(7.1)$ & $115(24.1)$ & $<0.001$ \\
\hline BPJS (national) $)^{\star \star}$ & $73(20.1)$ & $2(1.8)$ & $75(15.7)$ & $<0.001$ \\
\hline Current smoker & $103(28.3)$ & $20(17.7)$ & $123(25.8)$ & 0.024 \\
\hline Former smoker & $118(32.4)$ & $56(49.6)$ & $174(36.5)$ & 0.001 \\
\hline Physical inactivity & $218(59.9)$ & $59(52.2)$ & $277(58.1)$ & 0.148 \\
\hline High-sugar intake & $202(55.5)$ & $46(40.7)$ & $248(52.0)$ & 0.006 \\
\hline High-salty food and MSG intake & $148(40.7)$ & $33(29.2)$ & $181(37.9)$ & 0.028 \\
\hline High-fried food intake & $221(60.7)$ & $68(60.2)$ & $289(60.6)$ & 0.919 \\
\hline Often reuse cooking oil & $190(52.2)$ & $29(25.7)$ & 219 (45.9) & $<0.001$ \\
\hline
\end{tabular}

Values are $\mathrm{n}(\%)$ or means $\pm \mathrm{SD}$, unless otherwise stated. Comparison of baseline characteristics was performed using independent-samples t-test for continuous variables and Pearson $\chi^{2}$ test for categorical variables.

*Values are medians (Q1-Q3). Comparison was performed using Mann-Whitney U test.

†Metabolic syndrome was defined using National Cholesterol Education Program Adult Treatment Panel III classification.

$\ddagger$ Parental history of CVD was positive, if patients have had either mother with CVD at the age under 65 years, or father with CVD at the age under 55 years, or second degree of family with history of premature sudden cardiac death.

§US\$1=Rp13 500 (Indonesian Rupiah). The cut-point based on the national average of decent-living minimum income in 2015.

१Comparison was done using Fisher's exact test.

${ }_{* \star}^{*}$ As a national health insurance, BPJS has been started since 1 January 2014.

ACS, acute coronary syndrome; Askes, asuransi kesehatan (civil servant insurance); BMI, body mass index; BP, blood pressure; BPJS, badan penyelanggara jaminan sosial (national insurance); CVD, cardiovascular disease; HDL-chol, high-density lipoprotein cholesterol; Jamkesda, jaminan kesehatan daerah (local insurance for poor people); Jamkesmas, jaminan kesehatan masyarakat (national insurance for poor people); Jamsostek, jaminan sosial tenaga kerja (company insurance); LDL-chol, low-density lipoprotein cholesterol; MSG, mono-sodium glutamate; SCAD, stable coronary artery disease.

Table 1 shows the baseline characteristics of patients with CAD. As presented, patients with CAD in Indonesia had high levels of systolic blood pressures, fasting plasma glucose and low-density lipoprotein (LDL) cholesterol, and low level of high-density lipoprotein cholesterol.
More than half of these patients had metabolic syndrome but did not have central obesity. Most came from rural areas and from low and middle socioeconomic status, more often were current or former smokers, had poor dietary habits with high consumption of sugar and deep 
Table 2 Clinical presentation at hospital admission ${ }^{1}$

\begin{tabular}{|c|c|c|c|c|}
\hline & ACS & SCAD & Total & \\
\hline Variables & $(n=364)$ & $(n=113)$ & $(n=477)$ & $P$ values \\
\hline \multicolumn{5}{|l|}{ Prehospital } \\
\hline Previous hypertension & 268 (73.6) & 90 (79.6) & $358(75.1)$ & 0.196 \\
\hline On medication of hypertension & $156(42.9)$ & $55(48.7)$ & $211(44.2)$ & 0.277 \\
\hline Previous MI & $126(34.6)$ & $38(33.6)$ & $164(34.4)$ & 0.847 \\
\hline Previous stroke & $27(7.4)$ & $9(8.0)$ & $36(7.5)$ & 0.848 \\
\hline Previous CAG & $48(13.2)$ & $21(18.6)$ & $69(14.5)$ & 0.154 \\
\hline Previous $\mathrm{PCl}$ & $14(3.8)$ & $13(11.5)$ & $27(5.7)$ & 0.002 \\
\hline \multicolumn{5}{|l|}{ In hospital } \\
\hline STEMI & $211(58.0)$ & NA & $211(44.2)$ & NA \\
\hline NSTE-ACS & $153(42.0)$ & NA & $153(32.1)$ & NA \\
\hline Diabetes mellitus & $112(30.8)$ & $35(31.0)$ & $147(30.8)$ & 0.967 \\
\hline With HF diagnosis/signs & $150(41.2)$ & $34(30.1)$ & $184(38.6)$ & 0.034 \\
\hline Atrial fibrillation* & $9(2.5)$ & $3(2.7)$ & $12(2.5)$ & 1.000 \\
\hline Left ventricle hypertrophy & $124(34.1)$ & $21(18.6)$ & $145(30.4)$ & 0.002 \\
\hline Echocardiography assessed & $210(57.7)$ & $52(46.0)$ & $262(54.9)$ & 0.029 \\
\hline $\operatorname{LVEF}(\%)$ & $45 \pm 13.2$ & $49.3 \pm 17.4$ & $45.8 \pm 14.2$ & 0.049 \\
\hline Troponin T $(\mu \mathrm{g} / \mathrm{L}) \dagger$ & $0.42(0.10-1.58)$ & $0.00(0.00-0.02)$ & $0.20(0.02-1.00)$ & $<0.001$ \\
\hline Haemoglobin (g/dL) & $13.6 \pm 2.1$ & $13.5 \pm 2.1$ & $13.6 \pm 2.1$ & 0.61 \\
\hline Haematocrit & $0.40 \pm 0.06$ & $0.41 \pm 0.14$ & $0.40 \pm 0.09$ & 0.296 \\
\hline Creatinine $(\mu \mathrm{mol} / \mathrm{L}) \dagger$ & $88.4(79.6-114.9)$ & $88.4(77.8-114.9)$ & $88.4(79.6-114.9)$ & 0.869 \\
\hline eGFR $<60 \mathrm{~mL} / \mathrm{min}$ & $108(29.7)$ & $41(36.3)$ & $149(31.2)$ & 0.185 \\
\hline \multicolumn{5}{|l|}{ Comorbidities } \\
\hline Concomitant stroke* & $18(4.9)$ & $3(2.7)$ & $21(4.4)$ & 0.3 \\
\hline With cardiogenic shock ${ }^{*}$ & $17(4.7)$ & $0(0.0)$ & $17(3.6)$ & 0.017 \\
\hline Concomitant pneumonia & $37(10.2)$ & $5(4.4)$ & $42(8.8)$ & 0.06 \\
\hline \multicolumn{5}{|l|}{ VD } \\
\hline Non-significant 1 - 2 VD $\ddagger$ & $27(7.4)$ & $12(10.6)$ & $39(8.2)$ & 0.666 \\
\hline $1 \mathrm{VD}$ & $45(12.4)$ & $20(17.7)$ & $65(13.6)$ & 0.738 \\
\hline $2 \mathrm{VD}$ & $30(8.2)$ & $15(13.3)$ & $45(9.4)$ & 0.954 \\
\hline $3 \mathrm{VD}$ & $53(14.6)$ & $41(36.3)$ & $94(19.7)$ & 0.007 \\
\hline$>3 \mathrm{VD}^{*}$ & $28(7.7)$ & $2(1.8)$ & $30(6.3)$ & 0.001 \\
\hline
\end{tabular}

Values are $\mathrm{n}(\%)$ or means $\pm \mathrm{SD}$, unless otherwise stated. Comparison was performed using independent-samples t-test for continuous variables and Pearson $\chi^{2}$ test for categorical variables.

${ }^{*}$ Comparison was done using Fisher's exact test.

†Values are medians (Q1-Q3). Comparison was done using Mann-Whitney U test. fDefined as $1 \%-49 \%$ lumen stenosis in at least one coronary vessel. ${ }^{17}$

ACS, acute coronary syndrome; CAG, coronary angiography; eGFR, estimated glomerular filtration rate; HF, heart failure; LVEF, left ventricular ejection fraction; MI, myocardial infarction; NA, not applicable; NSTE, non-ST-elevation; PCI, percutaneous coronary intervention; SCAD, stable coronary artery disease; STEMI, ST-segment elevation myocardial infarction; VD, vessel disease.

fried food, and had low physical activity. The clinical profiles at hospital admission are presented in table 2. Of all patients, $75.1 \%$ had previous hypertension, $34.4 \%$ had previous MI and $7.5 \%$ had a previous stroke. Patients diagnosed with STEMI, NSTEMI, UA and SCAD were $44.2 \%, 17.8 \%, 14.3 \%$ and $23.7 \%$, respectively. At hospital admission, $30.8 \%$ of patients had diabetes mellitus, $38.6 \%$ were diagnosed or presented with heart failure signs and
$31.2 \%$ had reduced renal function. Out of 273 patients with CAG, 169 (61.9\%) had multivessel disease. Among $262(54.9 \%)$ patients who underwent echocardiography, $24.0 \%$ had an LVEF $\leq 35 \%$.

Table 3 summarises invasive and pharmacotherapy managements during hospitalisation. Of 211 patients with STEMI, only $10(4.7 \%)$ underwent primary PCI and $13(6.2 \%)$ received thrombolysis for early reperfusion. 
Table 3 Managements in hospital from admission to 6 months

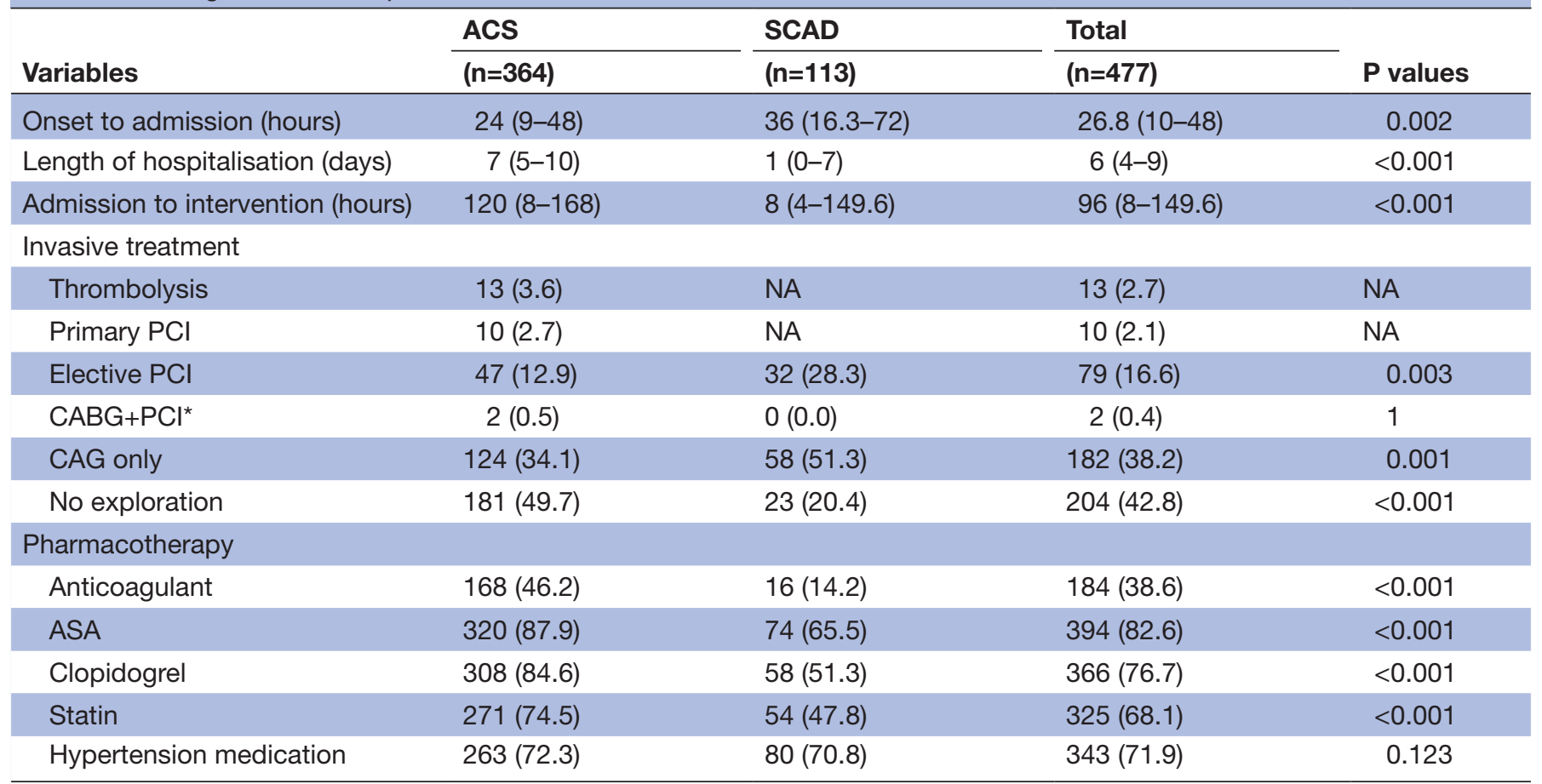

Values are $\mathrm{n}(\%)$ and medians (Q1-Q3). Comparison was done using Mann-Whitney $\mathrm{U}$ test for continuous variables and Pearson $\chi^{2}$ test for categorical variables.

${ }^{*}$ Comparison was done using Fisher's exact test.

ACS, acute coronary syndrome; ASA, acetylsalicylic acid; CABG, coronary artery bypass graft surgery; CAG, coronary angiography; NA, not applicable; $\mathrm{PCl}$, percutaneous coronary intervention; SCAD, stable coronary artery disease.

Meanwhile, of 477 patients, $42.8 \%$ had no exploration of CAG, and $19.1 \%$ underwent either PCI or CABG for revascularisation. Overall, there was a 24-36 hours time lapse between angina onset and hospital admission in ACS and SCAD groups, respectively $(\mathrm{p}=0.002)$. Patients with stable disease (SCAD) stayed shorter in hospital compared with patients with ACS $(\mathrm{p}<0.001)$.

Figure 2 describes the clinical outcomes at 30-day and 6-month follow-up. More patients with ACS died during hospitalisation compared with SCAD (12.6\% vs 5.3\%, $\mathrm{p}=0.029$ ). However, these SCAD group experienced 6-month adverse cardiovascular events more frequently compared with ACS group (25.7\% vs $15.7 \%, \mathrm{p}=0.043$ ). The rates of all-cause mortality in hospital, at 30 days and at 6 months were $10.9 \%, 2.5 \%$, and $7.3 \%$, respectively. In total, $189(39.6 \%)$ participants experienced at least one adverse event during the study period. A detailed description of MACE at 30 days and 6 months of these CAD patients is presented in table 4 .

Seven $(1.5 \%)$ participants were lost to follow-up. At 6 months, the survival rate was $78.9 \%$. The Kaplan-Meier curves showed significantly better survival in patients with statin $(\mathrm{p}=0.002)$, clopidogrel $(\mathrm{p}<0.001)$ and revascularisation $(\mathrm{PCI} / \mathrm{CABG})$ groups $(\mathrm{p}=0.001)$ compared with the respective counterparts. In subgroup analysis, patients with ACS and SCAD without PCI/CABG had the worst survival rates compared with those with revascularisation $(\mathrm{p}=0.002)$ (figure 3). Description of the most notable complaints or symptoms reported by all survivors is provided as online supplementary material.

\section{DISCUSSION}

The present study shows that patients with CAD in Indonesia are predominantly young males with high prevalence of cardiovascular risk factors. More than half of this cohort had metabolic syndrome and prior hypertension; and approximately one-third had prior MI and diabetes mellitus. The majority came from rural areas with a low or middle socioeconomic status, and had a history of smoking. These patients with CAD showed relatively severe illness, had significant time delay from angina onset to admission or intervention, and rarely received the guidelines-recommended treatment.

At baseline, compared with SCAD, patients with ACS were younger, had higher plasma glucose and LDL cholesterol, had lower income and educational level, were more often current smoker, and had poorer dietary habits. Further, we observed considerably more patients with ACS with diagnosis/signs of heart failure, with left ventricle hypertrophy and with lower LVEF than patients with SCAD. Likely as a result, those with ACS had poorer clinical outcomes mainly during hospitalisation and at 30-day follow-up compared with those with SCAD.

In contrast, at 6-month follow-up, more patients with SCAD had adverse cardiac events compared with ACS ( $p=$ 


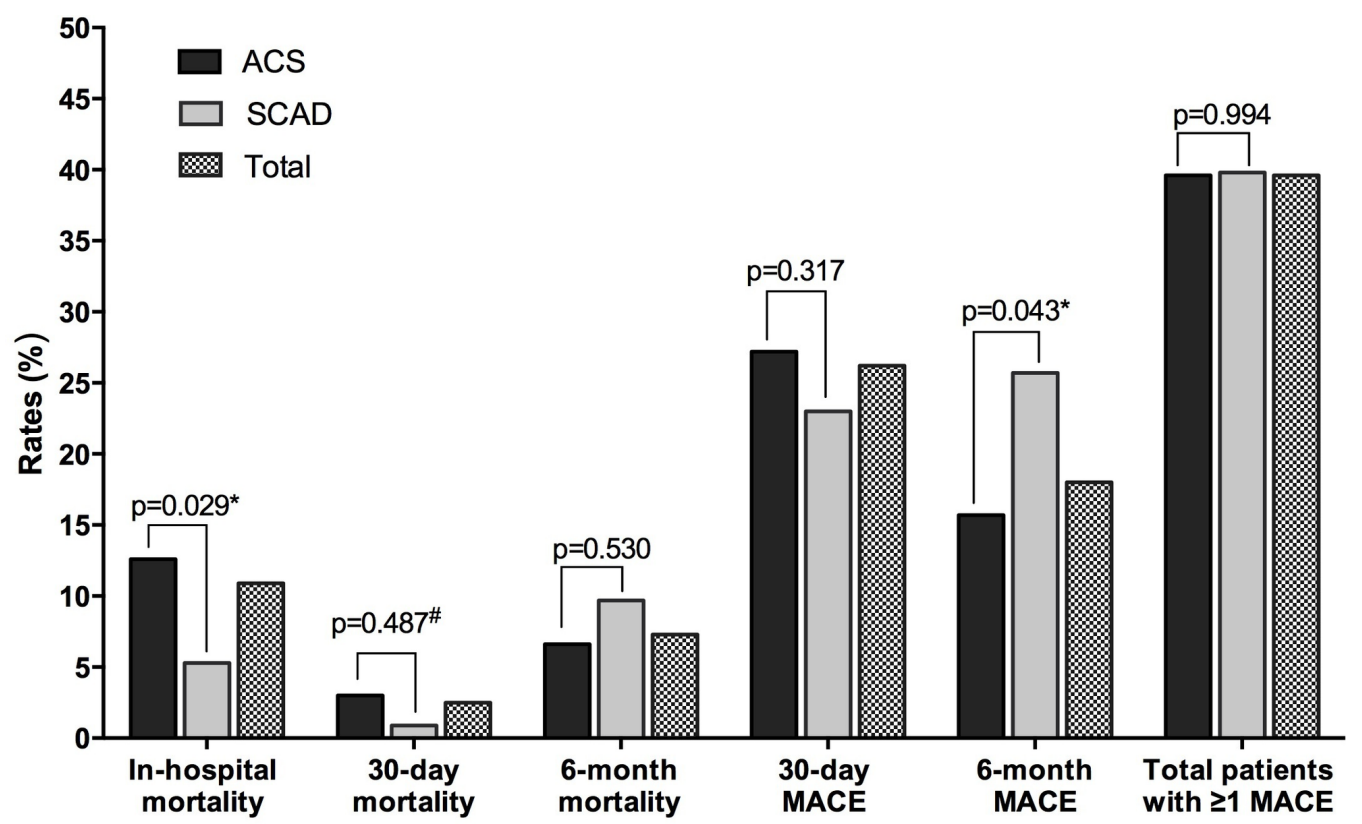

\begin{tabular}{|lccc|}
\hline Clinical Outcomes & $\begin{array}{c}\text { ACS } \\
(\mathrm{n}=364)\end{array}$ & $\begin{array}{c}\text { SCAD } \\
(\mathrm{n}=113)\end{array}$ & $\begin{array}{c}\text { Total } \\
(\mathrm{n}=477)\end{array}$ \\
\hline All-cause mortality & & & \\
In-hospital & $46(12.6)$ & $6(5.3)$ & $52(10.9)$ \\
$\begin{array}{l}30 \text {-day\# } \\
\text { 6-month }\end{array}$ & $11(3.0)$ & $1(0.9)$ & $12(2.5)$ \\
Total & $24(6.6)$ & $11(9.7)$ & $35(7.3)$ \\
Composite MACE & $\mathbf{8 1 ( 2 2 . 3 )}$ & $\mathbf{1 8 ( 1 5 . 9 )}$ & $\mathbf{9 9}(20.8)$ \\
30-day & & & \\
6-month & $99(27.2)$ & $26(23.0)$ & $125(26.2)$ \\
Total & $57(15.7)$ & $29(25.7)$ & $86(18.0)$ \\
Patients with $\geq 1$ MACE & $\mathbf{1 4 4 ( 3 9 . 6 )}$ & $\mathbf{4 5 ( 3 9 . 8 )}$ & $\mathbf{1 8 9 ( 3 9 . 6 )}$ \\
(including mortality) & & & \\
\hline
\end{tabular}

Values are $\mathrm{n}(\%)$. Comparison was performed using Pearson Chi-square test. \#Comparison was performed using Fisher's Exact test.

${ }^{*} \mathrm{p}<0.05$

Figure 2 Clinical outcomes at 30-day and 6-month follow-up. ACS, acute coronary syndrome; MACE, major adverse cardiovascular events; SCAD, stable coronary artery disease.

0.043). The most likely explanation is that these patients with SCAD were undertreated for secondary prevention and aftercare management. Out of 113 patients with SCAD, $34(30.1 \%)$ were admitted for congestive heart failure (CHF); and of 90 patients with SCAD with cardiac catheterisation, $58(64.4 \%)$ had multivessel CAD. Of those, only $32(55.2 \%)$ underwent elective PCI. Therefore, the lack access or adherence to the guidelines-recommended treatment (ie, elective PCI or CABG) and the lack of engagement to the long-term cardiovascular medications might largely contribute to these poorer outcomes. Meanwhile, in ACS, low access to an early invasive strategy was more likely to be associated with the high incidence of short-term death, chiefly in the first 30 days since admission.

In this study, we found that patients with ACS in Indonesia (mean age 57.5 years) were younger than patients with ACS in Japan (66.4 years) ${ }^{20}$ and in the Global Registry of Acute Coronary Events (GRACE) from 14 countries (65 years),${ }^{21}$ but equally young with patients with ACS in Malaysia (58.1 years) ${ }^{22}$ In these previous studies, the majority of patients were male $(>65 \%) \cdot{ }^{20-22}$

Hypertension, diabetes and smoking are the top three risk factors responsible for 3.5 million deaths in SouthEast Asia every year, and particularly afflicting the young population. ${ }^{24}$ In our ACS group, the proportions of 
Table 4 MACE during follow-up

\begin{tabular}{|c|c|c|c|}
\hline & At 30 days & At 6 months & Total \\
\hline Composite MACE & $(n=477)$ & $(n=477)$ & $(n=477)$ \\
\hline All-cause mortality & $64(13.4)$ & $35(7.3)$ & $99(20.8)$ \\
\hline $\begin{array}{l}\text { MI } \\
\text { rehospitalisation }\end{array}$ & $14(2.9)$ & $23(4.8)$ & $37(7.8)$ \\
\hline $\begin{array}{l}\text { HF } \\
\text { rehospitalisation }\end{array}$ & $1(0.2)$ & $6(1.3)$ & $7(1.5)$ \\
\hline Stroke & $2(0.4)$ & $4(0.8)$ & $6(1.3)$ \\
\hline Emergency CABG & $1(0.2)$ & $1(0.2)$ & $2(0.4)$ \\
\hline Repeat PCl & $5(1.0)$ & $3(0.6)$ & $8(1.7)$ \\
\hline Repeat CAG & $3(0.6)$ & $5(1.0)$ & $8(1.7)$ \\
\hline $\begin{array}{l}\text { First PCl } \\
\text { postdischarge }\end{array}$ & $23(4.8)$ & $3(0.6)$ & $26(5.5)$ \\
\hline $\begin{array}{l}\text { First CAG } \\
\text { postdischarge }\end{array}$ & $11(2.3)$ & $6(1.3)$ & $17(3.6)$ \\
\hline Stent thrombosis & $1(0.2)$ & $0(0.0)$ & $1(0.2)$ \\
\hline Total MACE & 125 (26.2) & $86(18.0)$ & $211(44.2)$ \\
\hline
\end{tabular}

Values are $\mathrm{n}(\%)$.

CABG, coronary artery bypass graft surgery; CAG, coronary

angiography; HF, heart failure; MACE, major adverse

cardiovascular events; MI, myocardial infarction; PCI,

percutaneous coronary intervention.

hypertension $(73.6 \%$ vs $47.1 \%)$ and diabetes mellitus $(30.8 \%$ vs $15.6 \%)$ were higher than in a similar multicentre study of patients with acute MI in France. ${ }^{23}$ The smoking-experience rate of patients with CAD in Indonesia $(62.3 \%)$ was strikingly higher than in Japan $(57.0 \%),{ }^{20} \mathrm{UK}(53.4 \%){ }^{19}$ and Malaysia $(47.0 \%) .{ }^{22}$ This finding is compatible with WHO Global Status Report in 2014. ${ }^{4}$

Asian populations are less obese than Western populations. ${ }^{44}$ Despite a much lower prevalence of overweight or obesity (22\%-26\% in South-East Asia vs $67 \%$ in UK and $70 \%$ in USA), raised blood glucose/diabetes mellitus is a pivotal risk factor in South-East Asia, reaching similarly high prevalence with the UK and USA. ${ }^{4}$ In contrast to the Western populations where diabetes is strongly associated with obesity, South-East Asia populations have a unique 'lean diabetic' phenotype. ${ }^{4}$ In terms of lifestyles, patients with $\mathrm{CAD}$ in Indonesia have a poor dietary pattern as reflected by high intakes of sugar and deep-fried foods. Our cohort showed physical inactivity levels $(58.1 \%)$ higher than the open population reported in Malaysia $(51.6 \%)$, UK $(40.0 \%)$ and USA $(35.0 \%){ }^{4}$

Overall at hospital admission, these patients with CAD showed relatively severe clinical features, with more renal insufficiency and heart failure. Our findings are in line with a previous report that, compared with the Netherlands, patients with STEMI in Indonesia more often presented with severe illness with heart failure signs and had a longer time delay between symptom onset and hospital admission. ${ }^{7}$ We found that the time lapse between symptom onset and admission was 24 (IQR 9-48) hours in patients with ACS. This was much longer compared with the GRACE study from 95 hospitals of 14 countries for patients with STEMI (139 (73-313) min), NSTEMI (190 (90-510) $\mathrm{min})$ or for UA (180 (90-435) $\mathrm{min}) .^{21}$

The time lapse from admission to intervention and length of stays were remarkably shorter in SCAD than in ACS group, because in our study the majority of referred patients $(n=50,71.4 \%)$ were classified as SCAD. These patients underwent an elective cardiac catheterisation and/or PCI and were then immediately returned to the referring hospitals. We did not track and record the duration of stay in the original hospitals. However, we assumed hospital stay duration in the referring hospitals to be relatively short because these patients usually underwent elective interventions for SCAD.

Longer time delay from the symptom onset to hospital admission remains one of the most crucial issues in cardiovascular services in the low-income and middle-income countries, ${ }^{25}$ particularly in Indonesia. The prominent problems appeared from the patients side were the lack of awareness of precursor symptoms, ${ }^{25} 26$ the negative perception and apprehension to the hospital, and financial problems. ${ }^{26}$ On the other hand, clinicians delay in making an early diagnosis and treatment in primary hospital or clinic, lack of collaboration between hospitals and doctors, administrative barriers, transportation problems and lack of ambulance organisation ${ }^{26}$ were also the influential factors for this extensive delay. Those who live in very remote areas, tend to manage their complaints with a visit to the local/traditional healer or non-traditional healthcare provider. As a result, there was a very low frequency of primary PCI and thrombolysis procedures conducted in our centre considering the 'golden time' period for effective reperfusion. A previous study reported that in the real-world practice, primary PCI as recommended by the guidelines is very difficult to perform in patients with STEMI in Indonesia; time delay is a critical issue for decision-making in choosing reperfusion strategy (primary PCI, fibrinolytic or the combination). ${ }^{26}$

We believed there are many unrecorded deaths due to CVD in this population because patients with more severe disease are likely to die before reaching the hospital and are not reported. This indicated that those with more stable and stronger physical endurance will have a chance to turn up alive in the hospital. We conclude that in general, haemodynamically unstable patientsfor logistic reasons (ie, the lack of transportation, interventional cardiologist and cath lab capacity) - first had to be stabilised prior to a rather planned intervention. Evidently, the infrastructure and resources were not sufficient to deal with emergency CAG followed by rescue PCI to treat the patients with acute CVD.

From hospital admission to 6 months, 59 (16.2\%) patients with ACS underwent primary or elective PCI. This is comparable with PCI following ACS in Malaysia $(13 \%-17 \%),{ }^{27}$ but much lower than Japan $(74 \%)$ and USA $(71 \%-87 \%) .{ }^{27}$ The total mortality rate at 30 days was 

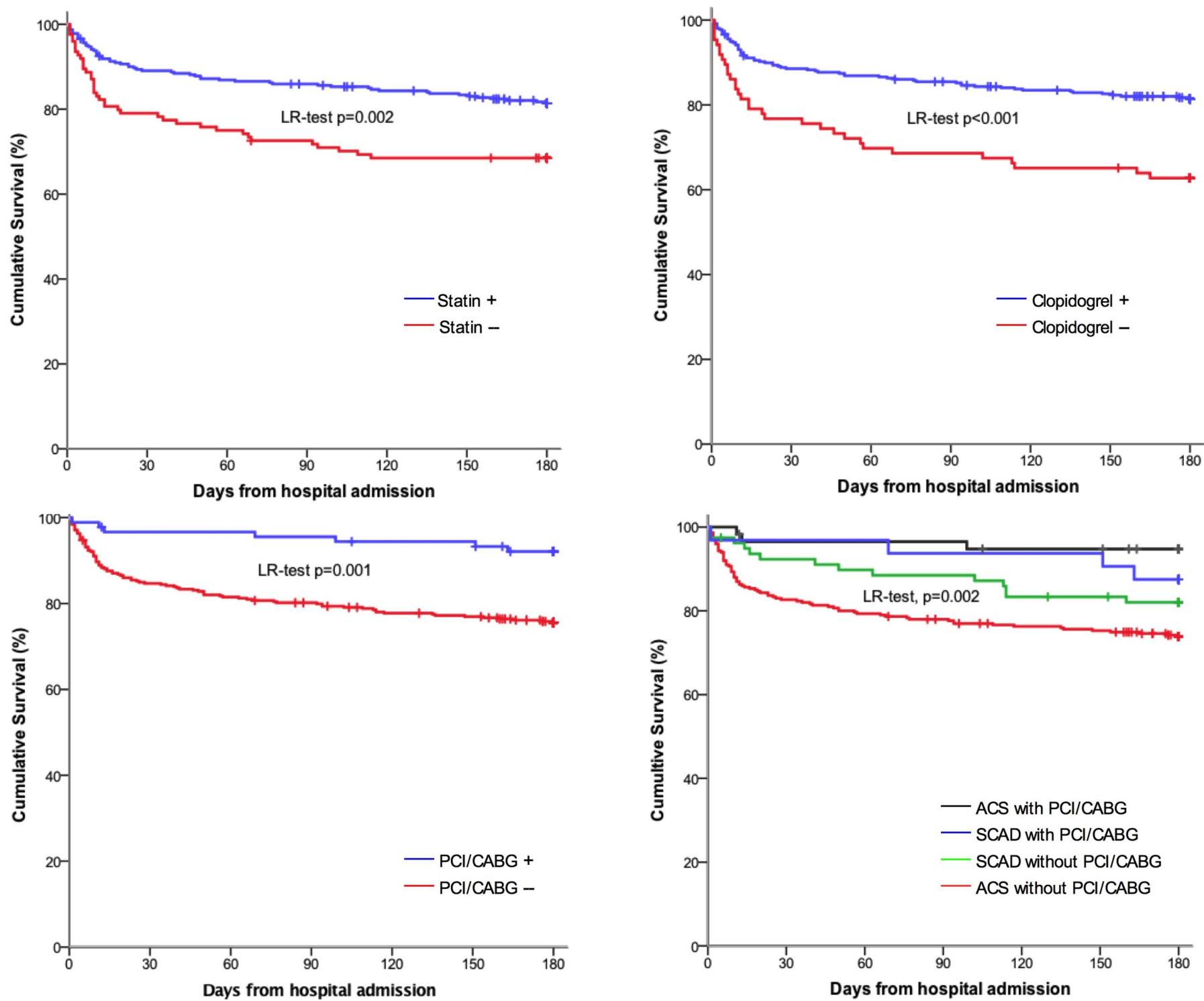

Figure 3 Kaplan-Meier curves for cumulative 6-month survival, comparing the guideline-treated versus non-guideline-treated groups in all participants and between diagnosis groups. Comparison was performed using LR (Mantel-Cox) test. ACS, acute coronary syndrome; CABG, coronary artery bypass graft surgery; LR, log rank; PCI, percutaneous coronary intervention; SCAD, stable coronary artery disease.

$15.7 \%$ in patients with ACS (figure 2), which is incredibly higher compared with patients in Japan $(3.4 \%),{ }^{20}$ and in the US patients after PCI intervention $(1.0 \%) .{ }^{28}$ Meanwhile, $24(6.6 \%)$ patients with ACS died between discharge and 6-month follow-up, and therefore higher than in the GRACE registry study $(4.7 \%) .^{29}$

Previous studies suggested that optimal revascularisation could prevent $\sim 32 \%$ of deaths by 6 months, ${ }^{27} 29$ and better 6-month survival was associated with the use of clopidogrel, statin and timely PCI or CABG. ${ }^{27}{ }^{30}$ Our data showed similar findings: the survival was significantly better in patients with statin, clopidogrel and revascularisation (PCI/CABG) compared with the non-guidelines-treated groups (see figure 3 ).

Patients undergoing PCI for ACS have higher shortterm and long-term mortality rates compared with those with SCAD undergoing elective PCI. ${ }^{31}$ In our study, patients with revascularisation (PCI or CABG) in ACS and SCAD groups were not significantly different in terms of survival $(p=0.236)$. However, when we compared the 6-month survival between patients with versus without revascularisation, there was an explicitly lower survival in those who did not undergo a revascularisation, both in ACS and SCAD groups ( $\mathrm{p}=0.002$ ) (figure 3 ).

Despite the fact that over $80 \%$ of mortality from CVD occurs in low-income and middle-income countries, ${ }^{32}$ these countries often do not have integrated primary healthcare programmes for early detection and treatments for cardiovascular risk factors to meet that challenge. In Indonesia, the poorest and very remote people are affected the most. Before the national health insurance era started in 2014, 80\% of Indonesian people were uncovered by a sufficient health insurance. ${ }^{7}$ Although the existing insurance schemes (Askes, Jamsostek, Jamkesmas 
and Jamkesda) conferred a large positive impact on access to healthcare facilities-notably for people from the low and middle socioeconomic level ${ }^{33-}$ still, the provided access to specific 'elitary treatments' were limited. ${ }^{34}$

Moreover, people who already suffered from CVD have also less access to an effective secondary prevention. ${ }^{8}$ Geographical and regional distances, low awareness and support from family members, and financial constraints were most likely responsible for the lack of access to this aftercare rehabilitation. According to the guidelines also adopted in Indonesia, most of these patients were not appropriately treated. Therefore, the stakeholders in Indonesia should focus on the improvement of primary and secondary prevention. Promotion of healthy lifestyles should be well established in order to reduce the prevalence of cardiovascular risk factors. The dissemination of first aid management for acute CVD as well as a rapid and standardised in-hospital response has to be established.

\section{Strengths and limitations}

There are some strengths and limitations in the present study:

- We had to exclude all patients who immediately died at emergency department and cardiovascular intensive care unit because we could not obtain a written informed consent from this group with the most critically ill conditions.

- The majority of our patients $(51.8 \%)$ were living in rural, often very remote areas. Hence, it was not possible to interview all patients by means of a face-toface interview for follow-up. In 239 (50.1\%) patients, phone calls were used, which may have led to less accurate data than obtained by direct questionnaire interview. However, we always verified the answers at the next visits or phone calls with a different interviewer to reduce inaccuracies.

- We excluded all patients with normal CAG, which were mostly females. Thus, our study may have overlooked the minor group of MI with no obstructive coronary atherosclerosis.

- Our study is, to our knowledge, the first in Indonesia with regard to clinical outcomes of hospitalised patients with CAD. Thus, we consider our study a quite unique effort to properly report on characteristics at admission and on short-term and mid-term outcomes in an attempt to identify opportunities to improve care.

\section{CONCLUSIONS}

Patients with CAD from a poor South-East Asian setting present themselves with predominantly unstable conditions of premature CAD. These patients show relatively severe illness, have significant time delay from symptom onset to admission or intervention, and most do not receive the guidelines-recommended treatment. Awareness of symptoms, prompt initial management of acute CVD, well-established infrastructures and resources both in primary and secondary hospital for CVD should be improved to reduce the high rates of 30-day and 6-month mortality and adverse outcomes in this population.

Author affiliations

${ }^{1}$ Department of Cardiothoracic Surgery, AMC Heart Center, Academic Medical

Center, University of Amsterdam, Amsterdam, The Netherlands

2Department of Physiology, Faculty of Medicine, University of Hasanuddin, Makassar, Indonesia

${ }^{3}$ Julius Center for Health Sciences and Primary Care, University Medical Center Utrecht, Utrecht University, Utrecht, The Netherlands

${ }^{4}$ Department of Cardiology, AMC Heart Center, Academic Medical Center, University of Amsterdam, Amsterdam, The Netherlands

${ }^{5}$ Department of Cardiology and Vascular Medicine, Faculty of Medicine, University of Hasanuddin, Makassar, Indonesia

Acknowledgements The authors gratefully acknowledge all participants who enrolled in this cohort study. Patients' family members and advisers are also acknowledged for their support and cooperation. We thank the staff of Cardiovascular Care Unit, Wahidin Sudirohusodo Hospital, Makassar for their contributions to the success of this research project and all research assistants for the data collection and data management. Special thanks for Fithriany Harry S. Farm, Apt., all nurses and nursing students in Puskesmas Batua (Batua Primary Healthcare Center), Makassar for their dedication to complete the continuation of the follow-up.

Contributors CSPMU, BAJMdM and AQ conceived the idea of the study and were responsible for the design of the study. AQ, AHA, IM, AAM and IP were responsible for the data collection and follow-up. $A Q$ was responsible for undertaking the data analysis and produced the tables and graphs. CSPMU, BAJMdM and JPSH provided input to the data analysis and interpretation. The initial draft of the manuscript was prepared by $A Q$, and was then circulated repeatedly to CSPMU, BAJMdM and JPSH for critical revision. All authors approved the final version of the manuscript.

Funding This work was supported by Directorate General of Higher Education/ Direktorat Jenderal Pendidikan Tinggi (DIKTI), Ministry of National Education Republic of Indonesia (grant number 600/E4.4/K/2011, 2011).

Disclaimer The study sponsor had no influence on the design of the study, analysis of data, interpretation of results or the decision to submit the manuscript for publication.

Competing interests None declared.

Patient consent Obtained.

Ethics approval The study protocol was approved by the Ethics Committee and Institutional Review Board of the Faculty of Medicine, University of Hasanuddin Makassar, Indonesia.

Provenance and peer review Not commissioned; externally peer reviewed.

Data sharing statement Dataset available from the corresponding author at a. qanitha@amc.uva.nl/myaqanitha@gmail.com.

Open access This is an open access article distributed in accordance with the Creative Commons Attribution Non Commercial (CC BY-NC 4.0) license, which permits others to distribute, remix, adapt, build upon this work non-commercially, and license their derivative works on different terms, provided the original work is properly cited and the use is non-commercial. See: http://creativecommons.org/ licenses/by-nc/4.0/

(c) Article author(s) (or their employer(s) unless otherwise stated in the text of the article) 2018. All rights reserved. No commercial use is permitted unless otherwise expressly granted.

\section{REFERENCES}

1. Dhillon PK, Jeemon P, Arora NK, et al. Status of epidemiology in the WHO South-East Asia region: burden of disease, determinants of health and epidemiological research, workforce and training capacity. Int J Epidemiol 2012;41:847-60.

2. World Health Organization. Regional office for South-East Asia. Noncommunicable diseases in the South-East Asia region: 2011 situation and response. New delhi: World Health Organization, 2011.

3. Ohira T, Iso H. Cardiovascular disease epidemiology in Asia: an overview. Circ J 2013;77:1646-52. 
4. Lam CSP. Heart failure in Southeast Asia: facts and numbers. ESC Heart Fail 2015;2:46-9.

5. Bowry AD, Lewey J, Dugani SB, et al. The burden of cardiovascular disease in low- and middle-income countries: epidemiology and management. Can J Cardiol 2015;31:1151-9.

6. Seligman B, Vedanthan R, Fuster V. Acute coronary syndromes in low- and middle-income countries: Moving forward. Int $J$ Cardiol 2016;217 Suppl:S10-S12.

7. Juwana YB, Wirianta J, Ottervanger JP, et al. Primary coronary intervention for ST-elevation myocardial infarction in Indonesia and the Netherlands: a comparison. Neth Heart J 2009;17:418-21.

8. World Health Organization. Media centre: cardiovascular diseases (CVDs). 2015 http://www.who.int/mediacentre/factsheets/fs317/en/.

9. Firman D. Use of coronary interventions in Indonesia. Singapore: AsiaPCR/SingLIVE, 2016.

10. Munawar M. Bifurcatio stenting in Indonesia. Singapore: AsiaPCR/ SingLIVE, 2015.

11. Pusat Data dan Informasi Kementerian Kesehatan Republik Indonesia. Situasi Kesehatan Jantung-Info DATIN 2014.

12. Telemedicine: sharing experiences and a way forward. Report of a regional consultation, Pyongyang, Democratic People's Republic of Korea. 2013.

13. Badan Pusat Statistik Republik Indonesia. Berita resmi statistik: persentase penduduk miskin maret 2015 Mencapai 11,22 Persen. https://www.bps.go.id/index.php/brs/1158.

14. Kumar A, Cannon CP. Acute coronary syndromes: diagnosis and management, part I. Mayo Clin Proc 2009;84:917-38.

15. Grech ED, Ramsdale DR. ABC of interventional cardiology, acute coronary syndrome: unstable angina and non-ST segment elevation myocardial infarction. BMJ 2003;326:1259-61.

16. Elbez $Y$, Cheong AP, Fassa AA, et al. Clinical outcomes in patients with stable coronary artery disease with vs. without a history of myocardial revascularization. Eur Heart J Qual Care Clin Outcomes 2016;2:23-32.

17. Pizzi C, Xhyheri B, Costa GM, et al. Nonobstructive versus obstructive coronary artery disease in acute coronary syndrome: a meta-analysis. J Am Heart Assoc 2016;5:e004185-14.

18. Ranthe MF, Carstensen L, Oyen N, et al. Family history of premature death and risk of early onset cardiovascular disease. J Am Coll Cardiol 2012;60:814-21.

19. Rathod KS, Jones DA, Gallagher S, et al. Atypical risk factor profile and excellent long-term outcomes of young patients treated with primary percutaneous coronary intervention for STelevation myocardial infarction. Eur Heart $J$ Acute Cardiovasc Care 2016;5:23-32.

20. Nakamura M, Yamashita T, Yajima J, et al. Clinical outcome after acute coronary syndrome in Japanese patients: an observational cohort study. J Cardiol 2010;55:69-76.
21. Fox KA, Goodman SG, Klein W, et al. Management of acute coronary syndromes. Variations in practice and outcome; findings from the Global Registry of Acute Coronary Events (GRACE). Eur Heart J 2002;23:1177-89.

22. Ahmad WA, Ramesh SV, Zambahari R. Malaysia-ACute CORonary syndromes Descriptive study (ACCORD): evaluation of compliance with existing guidelines in patients with acute coronary syndrome. Singapore Med J 2011;52:508-11.

23. Montalescot G, Dallongeville J, Van Belle E, et al. STEMI and NSTEMI: are they so different? 1 year outcomes in acute myocardial infarction as defined by the ESC/ACC definition (the OPERA registry). Eur Heart J 2006;28:1409-17.

24. Ueshima H, Sekikawa A, Miura K, et al. Cardiovascular disease and risk factors in Asia: a selected review. Circulation 2008;118:2702-9.

25. Lee ES, Vedanthan R, Jeemon P, et al. Quality improvement for cardiovascular disease care in low- and middle-income countries: a systematic review. PLoS One 2016;11:e0157036.

26. Dharma S, Juzar DA, Firdaus I, et al. Acute myocardial infarction system of care in the third world. Neth Heart J 2012;20:254-9.

27. Chan MY, Du X, Eccleston D, et al. Acute coronary syndrome in the Asia-Pacific region. Int J Cardiol 2016;202:861-9.

28. Hannan EL, Farrell LS, Walford G, et al. The New York state risk score for predicting in-hospital/30-day mortality following percutaneous coronary intervention. JACC Cardiovasc Interv 2013;6:614-22

29. Fox KA, Dabbous $\mathrm{OH}$, Goldberg RJ, et al. Prediction of risk of death and myocardial infarction in the six months after presentation with acute coronary syndrome: prospective multinational observational study (GRACE). BMJ 2006;333:1091.

30. Chew DP, Anderson FA, Avezum A, et al. Six-month survival benefits associated with clinical guideline recommendations in acute coronary syndromes. Heart 2010;96:1201-6.

31. Alcock RF, Yong AS, Ng AC, et al. Acute coronary syndrome and stable coronary artery disease: are they so different? Longterm outcomes in a contemporary $\mathrm{PCl}$ cohort. Int $J$ Cardiol 2013;167:1343-6.

32. Yusuf S, Rangarajan S, Teo K, et al. Cardiovascular risk and events in 17 low-, middle-, and high-income countries. N Engl J Med 2014;371:818-27.

33. Hidayat $\mathrm{B}$, Thabrany $\mathrm{H}$, Dong $\mathrm{H}$, et al. The effects of mandatory health insurance on equity in access to outpatient care in Indonesia. Health Policy Plan 2004;19:322-35.

34. Thabrany $\mathrm{H}$. Social health insurance in Indonesia: current status and the proposed national health insurance. Presented in Social Health Insurance Workshop WHO SEARO, New Delhi, March 13-15, 2003: Center for Health Economic Studies. University of Indonesia, 2003. 